\title{
O estímulo à criatividade em cursos de licenciatura
}

\author{
Rejane Arruda Ribeiro \\ Denise de Souza Fleith \\ Universidade de Brasília, Brasília-DF, Brasil
}

Resumo: Este estudo examinou a percepção de 82 professores universitários, de cursos de licenciatura, de instituições do Distrito Federal, acerca da extensão em que suas práticas docentes favorecem o desenvolvimento da criatividade de seus estudantes, bem como possíveis barreiras à sua criatividade pessoal. O estudo verificou ainda a percepção de 1396 estudantes acerca destas práticas docentes. Foram utilizados o Inventário de Práticas Docentes e o Inventário para Identificação de Barreiras à Criatividade Pessoal. Os resultados indicaram que a percepção de professores acerca das práticas docentes foi mais favorável comparada a dos estudantes. Além disso, a percepção de estudantes de semestres avançados foi mais favorável do que a de estudantes de semestres iniciais em relação aos fatores medidos pelo Inventário de Práticas Docentes. Estudantes de instituições particulares avaliaram mais positivamente fatores deste inventário do que estudantes de instituição pública. Falta de Tempo/Oportunidade foi apontada pelos professores como a principal barreira à criatividade pessoal.

Palavras-chave: Criatividade. Práticas docentes. Ensino superior. Cursos de licenciatura.

\section{Fostering creativity in teaching diploma programs}

\begin{abstract}
This study examined the perception of 82 professors from teaching diploma programs in the Federal District, Brazil, regarding the extent to which their educational practices favor the development of their students' creative expression, as well as potential barriers to their personal creativity. The study also examined the perception of 1396 students regarding their professors' educational practices. The Educational Practice and the Barrier Identification to Personal Creativity Inventories were applied. The results revealed that the professors' perception concerning to what extent their educational practices encourage students' creative expression was more favorable than that of students. Furthermore, the perception of students in advanced semesters was more favorable than that of those in first semesters in relation to the factors measured in the Educational Practice Inventory. Students from private institutions evaluated more positively the factors measured by this inventory than students from public institutions. Professors appointed lack of time/opportunity as the main barriers to personal creativity.
\end{abstract}

Keywords: Creativity. Educational practices. College education. Teaching diploma courses.

\section{El estímulo a la creatividad en cursos de licenciatura con especialización didáctica}

Resumen: Este estudio examinó la percepción de 82 profesores universitarios de cursos de licenciatura con especialización didáctica, de instituciones del Distrito Federal, acerca de la extensión en que sus prácticas docentes favorecen el desarrollo de la creatividad de sus estudiantes, así como posibles barreras a la creatividad personal. El estudio ha verificado aun la percepción de 1396 estudiantes acerca de estas prácticas docentes. Fueran utilizados el Inventario de Prácticas de Docencia y el Inventario para Identificación de Barreras a la Creatividad Personal. Los resultados indicaran que la percepción de profesores acerca de las prácticas de enseñanza fue más favorable comparada con de los estudiantes. Además, la percepción de estudiantes de semestres avanzados fue más favorable que la de estudiantes de semestres iniciales con relación a los factores medidos por el Inventario de Prácticas de Docencia. Estudiantes de instituciones particulares evaluaran más positivamente factores de este inventario de que los estudiantes de la institución pública. Falta de Tiempo/Oportunidad fue apuntada por los profesores como la principal barrera a la creatividad personal.

Palabras clave: Creatividad. Prácticas docentes. Enseño universitario. Especialización didáctica. 
Estudar qualquer fenômeno psicológico a partir da perspectiva do desenvolvimento humano requer entender o indivíduo como um ser complexo, inserido em múltiplos ambientes que o influenciam e são por ele influenciados. Nesse sentido, é válido ressaltar a necessidade de se compreender tais fenômenos de forma sistêmica e dinâmica (Aspesi, Dessen \& Chagas, 2005; Dessen \& Guedea, 2005).

$\mathrm{O}$ presente estudo propõe investigar a criatividade a partir dessa proposta. Autores como Amabile (1983, 1989), Alencar (1995, 2001a, 2002), Alencar e Fleith (2003a), Chagas, Aspesi e Fleith (2005), Choi (2004), Csikszentmihalyi (1988, 1996, 1999), Feldman (1999), Simonton (1999), Sternberg e Lubart (1991, 1995) e Wechsler (1993, 2002) consideram a relação indivíduo-ambiente um fator tão essencial para o desenvolvimento da criatividade, quanto as características intrapessoais. Stein (1974) menciona que promover a criatividade não envolve apenas estimular o indivíduo, mas também o ambiente social e as pessoas nele inseridas. Assim, a criatividade deve ser vista como resultado de configurações da subjetividade individual e da subjetividade social simultaneamente (Martínez, 2002b). Da mesma forma, Csikszentmihalyi (1996) considera que a "criatividade não ocorre dentro dos indivíduos, mas é resultado da interação entre os pensamentos do indivíduo e o contexto sócio-cultural. Criatividade deve ser compreendida não como um fenômeno individual, mas como um processo sistêmico" (p. 23).

Chagas, Aspesi e Fleith (2005) explicam que a promoção da criatividade está associada às interações estabelecidas pelos indivíduos na família, escola e sociedade. Um ambiente favorável ao desenvolvimento da criatividade está relacionado à qualidade da construção dessas interações e às experiências de vida dos indivíduos inseridos nesses contextos.

Nesse sentido, a escola adquire grande importância como local de estímulo e desenvolvimento das habilidades criativas. Alencar e Fleith (2003a) alertam para o fato da escola ainda oferecer, nos dias de hoje, uma educação estática, que privilegia a reprodução e memorização de conhecimentos, apesar do reconhecimento da importância da criatividade no contexto educacional. Assim, é urgente que se pense numa revisão dinâmica e criativa das práticas pedagógicas. Novaes (2003) também aponta a necessidade do processo de ensino-aprendizado ser conduzido por todos de maneira dinâmica e contínua, possibilitando que novas demandas educacionais sejam implementadas.

Também no ensino superior é debatida a necessidade de uma reorganização das estruturas que nele se apresentam a fim de proporcionar um ensino mais integrado, interdisciplinar, flexível e comprometido socialmente (Castanho \& Castanho, 2000; Cunha 1998; Ludke \& Cruz, 2005).

Assim, inúmeros autores têm se preocupado em discutir o papel das instituições de ensino superior na promoção da expressão da criatividade (Alencar \& Fleith, 2003a; Briceño, 1998; Castanho, 2000; Tolliver, 1985; Weschler, 2002). Castanho (2000), por exemplo, afirma que é necessário desenvolver no contexto universitário indivíduos com sensibilidade diante do mundo e mobilidade do pensamento, originalidade pessoal, atitude para transformar as coisas, espírito de análise e síntese e capacidade de organização. O papel do professor ocupa, então, um espaço fundamental nesse processo. Martínez (2002a) aponta a necessidade de se investir na formação de docentes comprometidos com a promoção do conhecimento e incentivo ao potencial criativo dos alunos. Wechsler (2002) conclui que é essencial formar professores criativos. Em suma, uma formação docente desejável envolveria "profissionais conscientes e críticos da realidade política e social, compromissados com a transformação desta realidade, que saibam utilizar o conteúdo científico (fundamentação teórica), a didática, a relação afetiva e a criatividade em nome desta transformação" (Forresti, 1999, p. 75).

É fundamental, portanto, que as instituições de ensino superior estejam continuamente atentas ao papel que desempenham no quadro atual da educação e na formação de futuros professores da educação básica (Picanço Diniz \& Borges, 2000). Para Weber (2003), a formação em nível superior é um dos fatores mais importantes no processo de profissionalização do professor da educação básica.

O Ministério da Educação (Brasil, 2003), em uma publicação sobre o perfil dos professores do 
Brasil, apontou que os cursos de graduação que oferecem licenciatura no Brasil são os que apresentam maior número de não preenchimento de vagas, tanto na rede pública quanto na particular. Estes dados sugerem o desinteresse relativo à opção pela licenciatura. Em comparação com os demais cursos, a concorrência por áreas que oferecem licenciatura é menor. Desta forma, é inegável a importância da formação de professores quando se reporta para a relevância da educação básica, onde atuarão, visando mais do que a reprodução de informação (Brasil, 2001).

Segundo Lara, Mosqueira e Ramos (1998), o professor idealizado surgirá a partir de um processo de formação profissional longo e enriquecedor, que permitirá uma prática consciente e comprometedora socialmente. Tessaro e Guzzo (2004) argumentam que "não bastam apenas escolas, mais vagas para alunos, melhor estrutura física, é preciso um professor que seja capaz de ensinar os alunos e transformá-los em cidadãos críticos e criativos" (p. 159). Para isso, segundo Ruiz (2004), é necessário que haja professores universitários, modelos para seus estudantes, docentes do futuro, motivados a aprender sempre e que busquem se aperfeiçoar e trazer inovações favoráveis para a sala de aula, sendo fundamental um profissional criativo e cheio de entusiasmo pelo processo de ensino-aprendizagem.

Entretanto, segundo Martínez (2002a), o tema criatividade é minimamente abordado em instituições formadoras de professores. Em sua maioria, a criatividade não é entendida como conteúdo específico e passível de organizações metodológicas para o seu desenvolvimento. Dessa forma, o ensino superior não oferece ferramentas direcionadas à expressão criativa para que o professor as utilize como instrumento em sala de aula e conteúdo a ser transmitido. Fleith (2000) explica que os professores, embora reconheçam a importância de se estimular a criatividade em sala de aula, implementam de maneira intuitiva práticas favoráveis ao potencial criador. A escassez de informação sobre criatividade e as lacunas na formação do professor explicam esse quadro.

Wechsler (2002) avalia que os fatores que inibem a criatividade, além da falta de preparo do professor, são as barreiras pessoais que o impede de ousar e buscar estratégias novas de ensino. Assim, a autora completa que muitos têm medo ou estão acomodados para enfrentar ou buscar propostas novas ao que fazem. Em um estudo conduzido por Alencar, Fleith e Martínez (2003), investigaram-se barreiras à criatividade pessoal entre estudantes universitários do Brasil e México. Os dados indicaram que a barreira mais freqüente apontada pelos estudantes foi falta de tempo e oportunidade para criar. Observou-se, ainda, falta de motivação como uma barreira mais mencionada pelos estudantes mexicanos em comparação com os brasileiros.

Estudos foram feitos para verificar a expressão criativa no ensino superior, porém, a maioria dos estudos volta-se mais para a percepção dos estudantes do que dos professores. Da mesma forma, nos estudos encontrados referentes a esse tema, é investigada a percepção de professores e estudantes universitários de diversos cursos, mas não especificamente os de licenciatura. Alencar (1997) investigou a percepção dos estudantes universitários quanto ao estímulo à criatividade por parte de seus professores. O estudo evidenciou que os professores pouco incentivam a criatividade, e que os programas das disciplinas não favorecem a expressão e o desenvolvimento da criatividade do estudante.

Joly e Guerra (2004) verificaram o desempenho em compreensão de leitura e a percepção de barreiras à criatividade pessoal por parte de 121 universitários ingressantes. De modo geral, foi verificado que os estudantes consideraram a falta de tempo e oportunidade para criar como a barreira pessoal mais significante. Da mesma forma, Alencar, Fleith e Virgolim (1995) verificaram a percepção de estudantes universitários e professores referentes a barreiras à criatividade pessoal. $\mathrm{O}$ estudo apontou como barreiras, a ausência de estímulo ao desenvolvimento do potencial criativo por parte dos agentes socializadores, timidez, falta de autoconfiança e medo de errar e ser criticado.

Tendo em vista a importância da criatividade na formação e prática docente, conduzimos o presente estudo com o objetivo de examinar a percepção de professores universitários, de cursos de licenciatura de instituição pública e particular do Distrito Federal, acerca da extensão em que suas práticas docentes favorecem o desenvolvimento da criatividade de seus 
estudantes, bem como possíveis barreiras à sua criatividade pessoal. $\mathrm{O}$ estudo verificou ainda a percepção de estudantes sobre estas práticas docentes.

\section{Método}

\section{Delineamento}

Foi utilizado um delineamento fatorial (Gall, Borg \& Gall, 1996) para responder as questões de pesquisa do presente estudo. As variáveis independentes foram: gênero (feminino e masculino), área de conhecimento (Humanidades, Ciências e Saúde), tipo de instituição de ensino superior (pública e particular), semestre em curso (estudantes que cursavam do $1^{\circ}$ ao $5^{\circ}$ semestre e estudantes que cursavam do $6^{\circ}$ semestre em diante) e grupo (grupo de estudantes, grupo de professores e grupo de professores se colocando na perspectiva do aluno). As variáveis dependentes investigadas foram: práticas docentes que favorecem a criatividade dos alunos (Incentivo a Novas Idéias, Clima para Expressão de Idéias, Avaliação e Metodologia de Ensino e Interesse pela Aprendizagem do Aluno) e barreiras pessoais à criatividade (Inibição/Timidez, Falta de Tempo/Oportunidade, Repressão Social e Falta de Motivação).

\section{Participantes}

Participaram do estudo 82 professores universitários de instituições de ensino público e particular no Distrito Federal e 1396 estudantes que cursavam uma disciplina de graduação ministrada por estes professores. Dada a dificuldade de seleção randômica dos participantes, uma vez que a participação dos sujeitos no projeto foi voluntária, uma amostra de conveniência foi utilizada (Gall, Borg \& Gall, 1996).

Dos 82 professores, a idade média dos professores foi 42 anos, variando de 25 a 67 anos. $\mathrm{O}$ tempo de experiência no magistério dos participantes do estudo variou de 3 meses a 36 anos, sendo a média 13 anos de experiência de ensino. Um professor não respondeu esta questão. Outras informações referentes aos professores participantes são apontadas a seguir, na Tabela 1 .
Tabela 1

Quantidade e percentual dos professores por gênero, area de conhecimento, instituiçäo que leciona e nivel de escolaridade

\begin{tabular}{|c|c|c|c|}
\hline \multicolumn{2}{|c|}{ Variáveis independentes } & \multirow{2}{*}{$\frac{n}{59}$} & \multirow{2}{*}{$\frac{\%}{72,0}$} \\
\hline \multirow{2}{*}{ Gênero } & Masculino & & \\
\hline & Feminino & 23 & 28,0 \\
\hline \multirow{5}{*}{$\begin{array}{l}\text { Area de } \\
\text { conhecimento } \\
\text { que leciona } \\
\text { Instituição que } \\
\text { leciona }\end{array}$} & Ciências & 43 & 52,4 \\
\hline & Humanidades & 26 & 31,7 \\
\hline & Saúde & 13 & 15,9 \\
\hline & Pública & 35 & 42,7 \\
\hline & Particular & 47 & 57,3 \\
\hline \multirow{7}{*}{$\begin{array}{l}\text { Nivel de } \\
\text { escolaridade }\end{array}$} & Superior completo & 4 & 4,9 \\
\hline & Especialização em curso & 1 & 1,2 \\
\hline & Mestrado em curso & 1 & 1,2 \\
\hline & Mestrado completo & 22 & 26,8 \\
\hline & Doutorado em curso & 10 & 12,2 \\
\hline & Doutorado completo & 40 & 48,8 \\
\hline & Não informaram & 4 & 49,0 \\
\hline
\end{tabular}

Foi adotada a classificação da Universidade de Brasília para os cursos analisados neste estudo. $\mathrm{Na}$ área de Ciências, os cursos foram de Biologia, Matemática, Física e Química; na área de Humanidades, Filosofia, Letras, História e Geografia; e na área de Saúde, Educação Física. Com relação aos estudantes que participaram da pesquisa, a idade média foi 24 anos, variando de 17 a 62 anos. A Tabela 2 apresenta a caracterização desses estudantes.

\section{Instrumentos}

Inventário de Práticas Docentes (Alencar \& Fleith, 2004b). Este Inventário foi utilizado para avaliar a extensão em que o professor universitário considerava que apresentava comportamentos que favoreciam o desenvolvimento e expressão das habilidades criativas de seus estudantes. Foi ainda solicitado ao professor que se colocasse no lugar dos estudantes e avaliasse a extensão em que sua prática docente tem contribuído para o desenvolvimento da criatividade discente. $\mathrm{O}$ mesmo instrumento foi respondido pelos universitários com vistas a avaliar a 
Tabela 2

Quantidade e percentual dos alunos por genero, área de conhecimento, instituição que estuda e semestre em curso

\begin{tabular}{llrr}
\hline Variáveis independentes & n & $\%$ \\
\hline \multirow{4}{*}{ Gênero } & Masculino & 694 & 49,7 \\
& Feminino & 690 & 49,4 \\
& Não responderam & 12 & 0,9 \\
Area de & Ciências & 695 & 49,8 \\
Conhecimento & Humanidades & 426 & 30,5 \\
& Saúde & 275 & 19,7 \\
Instituição de & Pública & 588 & 42,1 \\
ensino que estuda & Particular & 808 & 57,9 \\
& $1^{\circ}$ ao $5^{\circ}$ semestre & 814 & 58,4 \\
Semestre em Curso & $6^{\circ}$ sem em diante & 573 & 41,0 \\
& Não responderam & 9 & 0,6 \\
\hline
\end{tabular}

percepção destes quanto ao grau de incentivo a diferentes aspectos da criatividade por parte do seu professor que respondeu ao instrumento.

O Inventário é composto de 37 itens que avaliam os seguintes fatores: Incentivo a Novas Idéias (Fator 1), Clima para Expressão de Idéias (Fator 2), Avaliação e Metodologia de Ensino (Fator 3) e Interesse pela Aprendizagem do Aluno (Fator 4). A título de ilustração, apresentamos um item de cada um desses fatores.

Fator 1 (Incentivo a Novas Idéias):

Cultiva nos alunos o gosto pela descoberta e busca de novos conhecimentos.

Fator 2 (Clima para Expressão de Idéias):

Cria um ambiente de respeito e aceitação pelas idéias dos alunos.

Fator 3 (Avaliação e Metodologia de Ensino):

Utiliza formas de avaliação que exigem do aluno apenas a reprodução do conteúdo dado em classe ou contido nos livros-texto.

Fator 4 (Interesse pela Aprendizagem do Aluno):

Oferece informações importantes e interessantes relativas ao conteúdo da disciplina.
Cada um dos itens foi respondido em uma escala de 5-pontos, que variava de "discordo plenamente" até "concordo plenamente". Os coeficientes alfa de fidedignidade para os quatro fatores variaram de 0,72 a 0,93 . O estudo de validação do instrumento foi feito com base nas respostas de estudantes do ensino superior.

Inventário para Identificação de Barreiras à Criatividade Pessoal (Alencar, 1999). Este instrumento foi empregado a fim de investigar as barreiras da expressão à criatividade pessoal dos professores universitários participantes do estudo. Ele é composto por 66 itens de frases afirmativas e suas respostas apresentadas em escala de 5-pontos, variando de "discordo plenamente" até "concordo plenamente". Quatro fatores foram determinados pela análise fatorial: Inibição/Timidez (Fator 1), Falta de Tempo/Oportunidade (Fator 2), Repressão Social (Fator 3) e Falta de Motivação (Fator 4).

Exemplos de itens do Fator 1 são: fosse menos tímido(a) para expor minhas idéias; não tivesse medo de expressar o que penso. São exemplos de itens do Fator 2: tivesse mais oportunidade de pôr em prática as minhas idéias; tivesse tempo para elaborar minhas idéias. Alguns itens que integram o Fator 3 são: não tivesse recebido uma educação rígida; tivesse tido mais oportunidade para errar sem ser taxado(a) de burro(a) ou idiota. Exemplos de itens do Fator 4 são: tivesse mais entusiasmo; concentrasse mais no que faço. Os coeficientes alfa de fidedignidade obtidos para os fatores variaram de 0,85 a 0,91 .

\section{Procedimentos}

Foi estabelecido contato com os professores e/ou coordenadores de distintos cursos, pessoalmente, por correio eletrônico ou telefone, no sentido de solicitar a colaboração no projeto. Após aceitar colaborar no projeto, solicitou-se a cada professor que marcasse um horário durante uma de suas aulas para que os seus alunos pudessem responder ao instrumento, sugerindo-lhe também que respondesse ao instrumento no mesmo horário.

No que diz respeito aos professores, em alguns casos, eles respondiam ao instrumento posterior- 
mente, em função de sua disponibilidade. Realizouse uma aplicação coletiva do instrumento aos estudantes. Foi assegurado aos participantes do estudo o caráter confidencial de suas respostas.

\section{Análise de Dados}

Foram utilizadas análise descritiva, análise de variância multivariada (MANOVA) e, em função do número reduzido de professores participantes do estudo, utilizou-se a análise de variância univariada (ANOVA). Antes das ANOVA e MANOVA terem sido efetuadas, foram examinados os requisitos necessários para a realização das análises, tais como normalidade, linearidade e homogeneidade de variância. Todos os requisitos foram atendidos.

\section{Resultados}

Considerando-se a percepção de professores, estudantes e professores na posição de estudantes

Tabela 3

Média e desvio-padräo relativos à percepçäo dos professores, estudantes e professores se colocando na perspectiva dos estudantes nos fatores do inventário de práticas docentes

\begin{tabular}{|c|c|c|c|}
\hline Fatores & & $\mathrm{M}$ & DP \\
\hline \multicolumn{4}{|c|}{ Incentivo a Novas Idéias } \\
\hline & Professores & 4,43 & 0,46 \\
\hline & Estudantes & 3,83 & 0,73 \\
\hline & Professores b & 4,11 & 0,63 \\
\hline \multicolumn{4}{|c|}{ Clima para Expressão de Idéias } \\
\hline & Professores & 4,49 & 0,40 \\
\hline & Estudantes & 4,03 & 0,70 \\
\hline & Professores b & 4,32 & 0,53 \\
\hline \multicolumn{4}{|c|}{ Avaliação e Metodologia de Ensino } \\
\hline & Professores & 3,75 & 0,86 \\
\hline & Estudantes & 3,17 & 0,81 \\
\hline & Professores b & 3,42 & 0,87 \\
\hline \multicolumn{4}{|c|}{ Interesse pela Aprendizagem do Aluno } \\
\hline & Professores & 4,45 & 0,44 \\
\hline & Estudantes & 3,92 & 0,65 \\
\hline & Professores b & 4,24 & 0,59 \\
\hline
\end{tabular}

acerca da extensão em que práticas docentes favorecem a criatividade em sala de aula, nota-se que as médias mais altas foram obtidas no Fator 2 (Clima para Expressão de Idéias) e Fator 4 (Interesse pela Aprendizagem do Aluno) e a média mais baixa no Fator 3 (Avaliação e Metodologia de Ensino), conforme a Tabela 3 .

A avaliação dos professores acerca das barreiras à criatividade pessoal revelou que a média mais alta foi obtida no Fator 2 (Falta de Tempo/ Oportunidade) e a média mais baixa no Fator 3 (Repressão Social), conforme a Tabela 4.

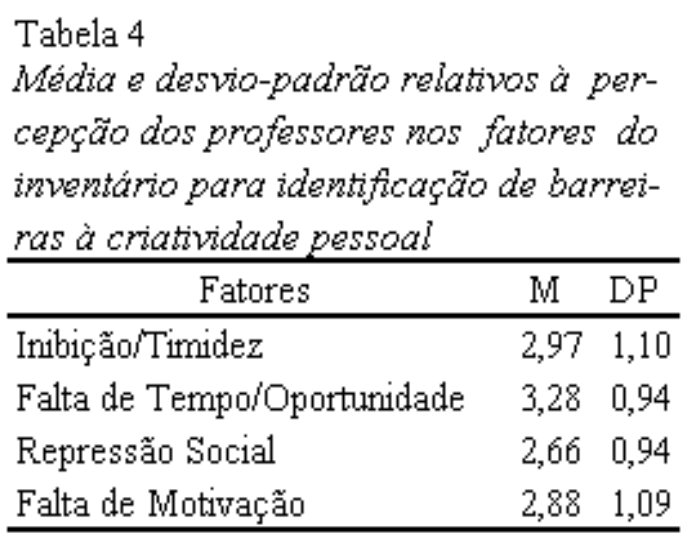

Investigou-se ainda se havia diferenças entre a percepção de estudantes, professores e professores se colocando na posição de estudantes em relação às práticas docentes que favorecem o desenvolvimento da criatividade em sala de aula. Os resultados da análise multivariada de variância (MANOVA) indicaram que há diferenças significativas entre os grupos (Wilks 'Lambda=0,951; $p=0,0001$ ). A análise de variância univarida (ANOVA), utilizada como post $h o c$, indicou diferenças significativas em relação ao Fator 1 (Incentivo a Novas Idéias) $(F[2,1223]=24,040$; $p=0,0001$ ), ao Fator 2 (Clima para Expressão de Idéias) $(\mathrm{F}[2,1223]=17,696 ; p=0,0001)$, ao Fator 3 (Avaliação e Metodologia de Ensino) (F[2,1223]= 17,$048 ; p=0,0001$ ) e ao Fator 4 (Interesse pela Aprendizagem do Aluno) $(\mathrm{F}[2,1223]=25,477 ; p=$ 0,0001).

Os resultados apontaram que os professores avaliaram mais positivamente o Fator $1(M=4,43$; $D P=0,45)$ do que os seus estudantes $(M=3,83 ; D P=$ $0,73)$. De forma similar, a percepção do professor na 
perspectiva do estudante acerca desta variável foi avaliada de maneira mais satisfatória $(M=4,06 ; D P=$ $0,62)$ do que a dos estudantes $(M=3,83 ; D P=0,73)$. Por fim, a percepção dos professores foi avaliada de maneira mais satisfatória $(M=4,43 ; D P=0,45)$ do que a dos próprios professores na perspectiva dos estudantes $(M=4,06 ; D P=0,62)$ no Fator 1 .

Os resultados revelaram também que os professores avaliaram mais positivamente o Fator 2 $(M=4,50 ; D P=0,40)$ do que os estudantes $(M=4,06$; $D P=0,69)$. Da mesma forma, a percepção dos professores na perspectiva do estudante acerca do Clima para Expressão de Idéias foi mais positiva $(M=$ $4,32 ; D P=0,53)$ do que a percepção dos estudantes $(M=4,05 ; D P=0,69)$.

Os resultados indicaram ainda que a percepção dos professores acerca do Fator 3 foi mais satisfatória $(M=3,77 ; D P=0,87)$ do que a dos estudantes $(M=$ $3,18 ; D P=0,82)$ e a dos professores na perspectiva do estudante $(M=3,41 ; D P=0,85)$. Os resultados assinalaram que a percepção dos professores foi mais positiva $(M=4,46 ; D P=0,44)$ do que a dos estudantes $(M=3,94 ; D P=0,65)$ no Fator 4 . Da mesma forma, a percepção dos professores na perspectiva do estudante foi mais satisfatória $(M=4,22 ; D P=0,56)$ do que a dos estudantes $(M=3,92 ; D P=0,65)$. Por fim, a avaliação dos professores em relação a este fator $(M=4,46 ; D P=0,44)$ foi melhor do que a avaliação dos próprios professores na perspectiva dos estudantes $(M=4,22 ; D P=0,56)$.

Os resultados da ANOVA não indicaram diferenças entre a percepção de professores do gênero masculino e feminino, de instituição pública e particular e de diferentes áreas em relação aos quatro fatores medidos pelo Inventário de Práticas Docentes (Tabela 5). Entretanto, os resultados assinalaram efeitos de interação significativa entre áreas de conhecimento e tipos de universidade em relação ao Fator 1 (Incentivo a Novas Idéias) $(\mathrm{F}[2,63]=3,843 ; p=0,027)$ e ao Fator 2 (Clima para Expressão de Idéias) $(\mathrm{F}[2,63]=5,792 ; p=0,005)$.

No Fator 1, a percepção dos professores de instituição particular na área de Ciências $(M=4,51$; $D P=0,52)$ foi mais satisfatória do que a dos professores de instituição pública que atuavam na mesma área $(M=4,21 ; D P=0,50)$. Por outro lado, os
Tabela 5

Valor de F e p nos fatores do inventário de práticas docentes por genero, tipos de instituição e area em relação à percepção dos professores

\begin{tabular}{llcl}
\hline \multicolumn{1}{c}{ Fatores } & & $\mathrm{F}$ & $p$ \\
\hline \multirow{2}{*}{ Incentivo a } & Gênero & 0,066 & 0,80 \\
Novas Idéias & Tipo de instituição & 0,236 & 0,63 \\
& Area & 0,917 & 0,41 \\
Clima para & Gênero & 0,040 & 0,84 \\
Expressão de & Tipo de instituição & 2,496 & 0,12 \\
Idéias & Area & 0,579 & 0,56 \\
Avaliação e & Gênero & 0,364 & 0,55 \\
Metodologia de & Tipo de instituição & 0,401 & 0,53 \\
Ensino & Area & 0,036 & 0,96 \\
Interesse pela & Gênero & 0,874 & 0,35 \\
Aprendizagem & Tipo de instituição & 1,858 & 0,18 \\
do Aluno & Area & 0,078 & 0,93 \\
\hline
\end{tabular}

professores de instituição pública das áreas de Humanidades e Saúde avaliaram mais positivamente este fator $\left(M_{H}=4,51 ; D P_{H}=0,37 ; M_{S}=4,89 ; D P_{S}=\right.$ $0,050)$ do que os professores de instituição particular das mesmas áreas $\left(M_{H}=4,36 ; D P_{H}=044 ; M_{S}=4,44\right.$; $\left.D P_{S}=0,36\right)$.

Com relação ao Fator 2, observou-se que os professores de instituições particulares das áreas de Ciências e de Saúde avaliaram esta dimensão de forma mais favorável $\left(M_{C}=4,60 ; D P_{C}=0,34 ; M_{S}=\right.$ $\left.4,75 D P_{S}=0,20\right)$ do que os de instituição pública das mesmas áreas $\left(M_{C}=4,33 ; D P_{C}=0,50 ; M_{S}=4,44\right.$ $\left.D P_{S}=0,10\right)$. Já os professores de instituição pública da área de Humanidades tiveram uma percepção mais positiva sobre o Clima para Expressão de Idéias $(M=4,55 ; D P=0,38)$ do que os de instituições particulares da mesma área $(M=4,25 ; D P=0,35)$.

Neste estudo foram investigadas ainda diferenças entre estudantes de distintas áreas, tipos de universidade e semestres cursados em relação aos fatores associados às práticas que favorecem a criatividade. Os resultados da análise multivariada de variância (MANOVA) indicaram ainda diferenças significativas entre estudantes de distintas áreas (Wilks' Lambda=0,971; $p=0,0001$ ), tipos de universidade (Wilks' Lambda=0,982; $p=0,001$ ) e 
semestres cursados (Wilks' Lambda=0,983; $p=0,0001$ ). Os resultados da análise de variância univariada revelaram diferenças significativas na percepção de estudantes de cursos distintos em relação ao Fator 1 (Incentivo a Novas Idéias) $(\mathrm{F}[2,1057]=12,853 ; p=0,0001)$, Fator 2 (Clima para Expressão de Idéias) $(\mathrm{F}[2,1057]=4,393 ; p=0,013)$, Fator 3 (Avaliação e Metodologia de Ensino) (F[2,1057]= $7,879 ; p=0,0001)$ e Fator 4 (Interesse pela Aprendizagem do Aluno $)(\mathrm{F}[2,1057]=7,982 ; p=0,0001)$.

Em relação ao Fator 1, observou-se que a percepção dos estudantes da área de Saúde foi mais satisfatória $(M=4,05 ; D P=0,67)$ do que a dos estudantes da área de Ciências $(M=3,75 ; D P=0,76)$ e de Humanidades $(M=3,81 ; D P=0,69)$.

Quanto ao Fator 2, apesar da análise de variância univariada ter indicado haver diferenças de percepção entre alunos de cursos distintos, o teste de Dunett não detectou diferenças significativas entre eles. Em relação ao Fator 3, pode-se notar que estudantes da área de Saúde avaliaram este fator mais satisfatoriamente $(M=3,36 ; D P=0,88)$ do que os estudantes da área de Ciências $(M=3,11 ; D P=$ $0,79)$. No que se refere ao fator 4 (Interesse pela Aprendizagem do Aluno), a percepção dos estudantes da área de Saúde foi mais satisfatória $(M=4,10 ; D P=$ $0,58)$ do que a percepção dos estudantes da área de Ciências $(M=3,86 ; D P=0,68)$ e de Humanidades $(M=3,90 ; D P=0,61)$.

A análise univariada de variância revelou ainda diferenças significativas entre estudantes de instituições pública e particulares em relação ao Fator $1(\mathrm{~F}[1,1057]=6,132 ; p=0,013)$ e Fator $3(\mathrm{~F}[1,1057]=$ 13,266; $p=0,0001)$. No Fator 1, os estudantes de instituições particulares avaliaram este fator de forma mais positiva $(M=3,94 ; D P=0,73)$ do que os de instituição pública $(M=3,69 ; D P=0,70)$. No que se refere ao Fator 3, os estudantes de instituições particulares avaliaram este fator de forma mais positiva $(M=3,33 ; D P=0,83)$ do que os de instituição pública $(M=3,01 ; D P=0,77)$.

A análise univariada de variância revelou também diferenças significativas entre alunos que cursavam do $1^{\circ}$ ao $5^{\circ}$ semestre e alunos que cursavam do $6^{\circ}$ semestre em diante em relação ao Fator 1 $(\mathrm{F}[1,1057]=8,011 ; p=0,005)$, Fator $2(\mathrm{~F}[1,1057]=$
$17,639 ; p=0,0001)$, Fator $3(\mathrm{~F}[1,1057]=6,336 ; p=$ $0,012)$ e Fator $4(\mathrm{~F}[1,1057]=8,840 ; p=0,003)$. No que diz respeito ao Fator 1, os resultados revelaram que a percepção dos estudantes que cursavam do $6^{\circ}$ em diante $(M=3,94 ; D P=0,72)$ foi mais satisfatória do que a percepção dos estudantes que cursavam do $1^{\circ}$ ao $5^{\circ}$ semestre $(M=3,75 ; D P=0,72)$.

Quanto ao Fator 2, os resultados apontaram que a percepção dos estudantes do $6^{\circ}$ semestre em diante $(M=4,19 ; D P=0,64)$ foi mais positiva do que a percepção dos estudantes de $1^{\circ}$ ao $5^{\circ}$ semestre $(M=$ $3,96 ; D P=0,71)$. No Fator 3 , ocorreu o mesmo. Os resultados apontaram uma percepção mais satisfatória dos estudantes de $6^{\circ}$ semestre em diante $(M=$ $3,30 ; D P=0,83)$ em relação à percepção dos estudantes que cursavam do $1^{\circ}$ ao $5^{\circ}$ semestre $(M=$ $3,11 ; D P=0,80)$. No que diz respeito ao Fator 4 , a percepção dos estudantes de semestres mais avançados $(M=4,03 ; D P=0,62)$ também foi mais satisfatória do que a percepção dos estudantes que cursavam semestres iniciais $(M=3,83 ; D P=0,65)$.

Por último, este estudo investigou se havia diferenças entre a percepção de professores do gênero masculino e feminino, de instituição de ensino superior pública e particular e de diferentes áreas no que se

Tabela 6

Valor de F e p nos fatores do inventário para identificação de barreiras à criatividade do pessoal do professor por gênero, tipos de instituição érea

\begin{tabular}{llcl}
\hline \multicolumn{1}{c}{ Fatores } & & $\mathrm{F}$ & $p$ \\
\hline \multirow{2}{*}{ Inibição / } & gênero & 0,049 & 0,83 \\
Timidez & tipo de instituição & 0,597 & 0,44 \\
& área & 1,661 & 0,20 \\
Falta de & gênero & 1,198 & 0,28 \\
Tempo / & tipo de instituição & 1,468 & 0,23 \\
Oportunidade área & 0,619 & 0,54 \\
& gênero & 0,284 & 0,60 \\
Repressão & tipo de instituição & 0,156 & 0,70 \\
Social & área & 1,649 & 0,20 \\
& gênero & 0,011 & 0,92 \\
Falta de & tipo de instituição & 0,344 & 0,56 \\
Motivação & área & 1,202 & 0,31 \\
\hline
\end{tabular}


refere às barreiras à criatividade pessoal. Os resultados indicaram que não há diferenças significativas, conforme a Tabela 6 .

\section{Discussão}

Os resultados deste estudo assinalaram que, tanto os estudantes, quanto os profesores, e professores se colocando no lugar dos alunos, avaliaram de forma mais satisfatória os itens relacionados ao fator Clima para Expressão de Idéias e Interesse pela Aprendizagem do Aluno. Por outro lado, os itens referentes à Avaliação e Metodologia de Ensino obtiveram as médias mais baixas. Os dados sugerem que os professores percebem a importância da promoção à criatividade, porém parecem ter dificuldade em adotar estratégias de ensino que favoreçam a criatividade discente. Esses dados corroboram o discurso de Martínez (2002a) que ressalta a desatenção dada à criatividade no ensino superior como um componente importante na formação profissional. A autora acrescenta que o estímulo à criatividade não é valorizado ou considerado uma necessidade nesse nível de ensino. Portanto, esse não é encarado no ensino superior como uma ferramenta que o professor pode utilizar para auxiliálo no planejamento das aulas e no incremento de suas práticas pedagógicas, com vistas a implementar metodologias e estratégias de incentivo à expressão criativa do estudante.

Esta desatenção pode ser explicada pelo fato de que muitos docentes e estudantes possuem idéias equivocadas a respeito da criatividade como, por exemplo, a crença de que a criatividade depende exclusivamente de fatores intrapessoais e inatos, não sendo possível seu desenvolvimento (Alencar, 2001a; Alencar \& Fleith, 2003a). Assim, a falta de informação adequada leva o docente a desconsiderar a criatividade como uma dimensão importante em sala de aula e conseqüentemente a não dispor de ferramentas de estímulo à criatividade neste contexto.

É interessante ressaltar que em todos os fatores do Inventário de Práticas Docentes, a percepção do professor e do docente no lugar do estudante foi mais positiva do que a dos estudantes. Esses dados convergem com os obtidos por Alencar e Fleith (2004a) que investigaram a percepção de professores e estudantes universitários em relação ao incentivo à criatividade utilizando o mesmo instrumento. Em outro estudo, Silva e Alencar (2003) verificaram a percepção de professores e estudantes de Enfermagem acerca das práticas docentes e sua relação com a criatividade. Os professores da amostra também apresentaram uma percepção mais positiva, comparados aos estudantes. Os dados sugerem que as respostas dos professores refletem muito mais um ideal de conduta docente em sala de aula do que o que realmente é implementado por eles.

Ao se comparar as respostas de professores de instituição pública e particular de distintas áreas de conhecimento (Ciências, Humanidades e Saúde), observaram-se diferenças em relação aos fatores Incentivo a Novas Idéias e Clima para Expressão de Idéias. No entanto, é importante ressaltar que a distribuição dos professores em três áreas distintas de conhecimento por tipo de instituição não foi balanceada. Por exemplo, o número de professores da área de Ciências (43, sendo 17 de instituição pública e 26 de instituições particulares) foi consideravelmente maior do que os da área de Saúde (13, sendo 3 de instituição pública e 10 de instituições particulares). Assim, os resultados de interação devem ser examinados em amostras maiores e balanceadas.

Com relação à percepção dos estudantes, constatou-se que os estudantes da área de Saúde avaliaram mais satisfatoriamente os fatores Incentivo a Novas Idéias e Interesse pela Aprendizagem do Aluno do que os da área de Ciências e Humanidades. É fundamental lembrar que a área de Saúde analisada no presente estudo inclui estudantes somente do curso de Educação Física, pois os demais cursos desta área (de acordo com a classificação adotada) não têm a opção de licenciatura para ensino fundamental e médio, foco deste estudo. O curso de Educação Física possui características diferenciadas dos cursos das áreas de Ciências (Química, Física e Matemática) e Humanidades (Geografia, História, Filosofia e Letras). A diversidade de espaços onde as aulas são ministradas e de metodologias de ensino assim como a dinâmica das aulas podem estimular a iniciativa e participação dos estudantes, interligar teoria e prática, incluir formas não tradicionais de avaliação e privilegiar diferentes formas de expressão. Isto se 
torna mais evidente a partir dos resultados referentes ao fator Avaliação e Metodologia de Ensino, melhor avaliados pelos os estudantes da área de Saúde em comparação com os da área de Ciências, por exemplo.

Observou-se, ainda, que os estudantes de instituições particulares obtiveram médias mais altas do que os de instituição pública nos fatores Incentivo a Novas idéias e Avaliação e Metodologia de Ensino, no que se refere às práticas de seus professores. Uma hipótese que explica esse dado seria a facilidade de acesso e diversidade de recursos que o docente de ensino superior particular tem para utilizar em sua disciplina, assim como a qualidade do espaço físico da sala de aula. Esses aspectos enriquecem o planejamento e a condução da disciplina. O uso de recursos diversificados possibilita ao professor diversificar suas estratégias de ensino, atendendo, assim, aos diferentes estilos de aprendizagem e de expressão discente (Fleith, 2002; Renzulli, 1992). A falta ou a dificuldade de acesso, por parte do professor, de recursos audiovisuais, laboratórios bem equipados e instalações físicas pouco adequadas, quadro bastante comum nas instituições públicas, desmotiva o professor e limita seu planejamento de aula.

Os resultados também apontaram para uma avaliação mais positiva dos estudantes de semestres mais avançados em relação às práticas docentes em todos os fatores. Três explicações plausíveis podem ajudar a entender esse cenário. A primeira seria o fato da maioria das disciplinas de semestres mais avançados possuir estruturas de aulas mais flexíveis e dinâmicas e apresentar um caráter mais prático à formação do estudante que está próximo de concluir seu curso. Além disso, o estudante pode cursar disciplinas mais direcionadas à sua área de interesse profissional. Já nos semestres iniciais, as disciplinas são mais teóricas ou são de outros departamentos, o que, a princípio, pode levá-los a não se identificarem com a disciplina, pois, muitas vezes, os professores não relacionam seu conteúdo ao curso de origem do estudante, tornando a disciplina sem importância e sem significado para esse. Esta situação acarreta em estudantes não envolvidos ou desinteressados pela disciplina, e, também contribui para que as aulas tenham sempre o mesmo padrão. Lüdke e Cruz (2005), ao discorrerem a respeito da separação entre a teoria e a prática na formação de professores, esclarecem que a teoria é apresentada inicialmente e a prática é realizada nos semestres finais. Segundo as autoras, esta separação é prejudicial, pois contribui para a fragmentação dos cursos e das disciplinas.

A segunda explicação é a de que, de modo geral, os alunos de semestres mais avançados possuem uma bagagem maior de conhecimentos e, por isso, estão mais preparados para debater sobre temas apresentados em aula. Além disso, muitos estudantes em fase final de curso já lecionam e assim contribuem com suas experiências nas aulas.

Por fim, com relação às barreiras à expressão da criatividade pessoal, o fator Falta de Tempo/ Oportunidade para criar foi o principal obstáculo apontado pelos professores. Resultado similar foi obtido por Alencar e Fleith (2003b) e Alencar, Oliveira, Ribeiro e Brandão (1996), segundo professores do ensino fundamental, médio e superior. O fator Falta de Tempo/ Oportunidade para criar também foi evidenciado por estudantes universitários em estudos conduzidos por Alencar (2001b) e Joly e Guerra (2004).

A atuação no ensino superior muitas vezes requer do professor envolvimento em diversas atividades acadêmicas e administrativas, restando pouco tempo para se dedicar à preparação das aulas. Além disso, o conteúdo extenso a ser coberto em várias disciplinas ministradas por ele limita o tempo de aula disponível para trabalhar o conteúdo de forma crítica e criativa. Alencar e Fleith (2003) chamam atenção ainda, para o enorme desperdício do talento criativo devido à falta de oportunidade para desenvolver e expressar este potencial. Na formação de professores, a ênfase tem sido no domínio de conteúdo específico da área e pouca atenção tem sido dada à aquisição de estratégias de ensino e técnicas de estimulação da criatividade em sala de aula.

Por este motivo, Falta de Tempo/Oportunidade para criar, "doença" do mundo contemporâneo, resultado do número excessivo de tarefas atribuídas ao profissional e da multiplicidade de papéis por ele exercidos, pode ajudar a entender a baixa avaliação, por parte dos professores e estudantes, do fator Avaliação e Metodologia de Ensino, medido pelo Inventário de Práticas Docentes. Ou seja, não há tempo suficiente para diversificar formas de 
avaliação, preparar planos de aulas alternativos e inovadores, variar estratégias de ensino, nem ouvir o aluno (Alencar \& Fleith, 2003a; Csikszentmihalyi, 1988, 1996, 1999; Feldman 1999; Feldman, Csikszentmihalyi \& Gardner, 1994; Novaes, 2001, 2003; Simonton, 1999), limitando, assim, o papel do professor como educador.

Concluindo, os resultados obtidos neste estudo assinalam a necessidade de se repensar a estrutura curricular de cursos de licenciatura de modo a incluir a criatividade como uma ferramenta de trabalho necessária para a formação docente. Se a criatividade é minimamente valorizada nos cursos de formação docente, dificilmente esta será implementada por estes novos profissionais nas turmas de educação básica. É fundamental que nos voltemos aos cursos de licenciatura quanto à necessidade do incentivo à expressão criativa do aluno. Promover uma formação docente voltada para a criatividade, na universidade, contribui tanto para a construção de jovens professores críticos e envolvidos socialmente, quanto para o desenvolvimento da expressão criativa de seus futuros alunos, crianças e adolescentes na educação básica.

Para aprofundarmos nossa compreensão acerca do desenvolvimento da criatividade no ensino superior, especialmente nos cursos de licenciatura, recomendamos: (a) a realização de estudos observacionais nas salas de aula do ensino superior nos cursos de licenciatura, a fim de investigar mais profundamente a extensão em que as práticas pedagógicas docentes favorecem a expressão criativa dos estudantes; (b) a condução de um estudo comparativo entre professores e estudantes universitários de cursos de licenciatura, bem como professores de educação básica da mesma área de conhecimento, a fim de investigar a extensão em que a criatividade é incorporada em sala de aula nos diferentes níveis de ensino; (c) a replicação do presente estudo, utilizando uma amostra maior e melhor balanceada de professores, a fim de que possíveis diferenças entre gênero, tipo de universidade e área de conhecimento sejam detectadas; e (d) a condução de um estudo qualitativo a respeito da importância da criatividade segundo o professor de cursos de licenciatura e da influência de barreiras internas e externas à criatividade na atuação docente.

\section{Referências}

Alencar, E. M. L. S. (1995). Criatividade. Brasília, DF: EdUnB.

Alencar, E. M. L. S. (1997). O estímulo à criatividade no contexto universitário. Psicologia Escolar e Educacional, 1, 29-37.

Alencar, E. M. L. S. (1999). Barreiras à criatividade pessoal: Desenvolvimento de um instrumento de medida. Psicologia Escolar e Educacional, 3, 123-132.

Alencar, E. M. L. S. (2001a). Criatividade e educação de superdotados. Petrópolis, RJ: Vozes.

Alencar, E. M. L. S. (2001b). Obstacles to personal creativity among university students. Gifted Education International, 15, 133-140.

Alencar, E. M. L. S. (2002). O contexto educacional e sua influência na criatividade. Linhas Críticas, 8, 165-178.

Alencar, E. M. L. S., \& Fleith, D. S. (2003a). Criatividade: Múltiplas perspectivas. Brasília, DF: EdUnB.

Alencar, E. M. L. S., \& Fleith, D. S. (2003b). Barreiras à criatividade pessoal entre professores de distintos níveis de ensino. Psicologia: Reflexão e Crítica, 16, 63-69.

Alencar, E. M. L. S., \& Fleith, D. S. (2004a). Creativity in university courses: Perceptions of professors and students. Gifted and Talented International, 19, 24-28.

Alencar, E. M. L. S., \& Fleith, D. S. (2004b). Inventário de práticas docentes que favorecem a criatividade no ensino superior. Psicologia: Reflexão e Crítica, 17, 105-110.

Alencar, E. M. L. S., Fleith, D. S. \& Martínez, A. M. (2003). Obstacles to personal creativity between Brazilian and Mexican students: A comparative study. The Journal of Creative Behavior, 31, 179-192. 
Alencar, E. M. L. S., Fleith, D. S., \& Virgolim, A. M. R. (1995). Fatores inibidores à criatividade em estudantes universitários e professores. In R. S. L. Guzzo, G. P. Witter, S. Pfomm Neto, E. Rosado \& S. Wechsler (Orgs.), O futuro da criança na escola, família e sociedade (pp. 105-109). Campinas, SP: Editora Átomo.

Alencar, E. M. L. S., Oliveira, A. C., Ribeiro, R., \& Brandão, S. N. (1996). Barreiras à expressão da criatividade entre profissionais da área de educação [Resumo]. Reunião Anual de Psicologia, 26 (p.113). Ribeirão Preto, SP: Sociedade Brasileira de Psicologia.

Amabile, T. M. (1983). The social psychology of creativity. New York: Springer.

Amabile, T. A. (1989). Growing up creative. Buffalo, NY: The Creative Education Foundation.

Aspesi, C. C, Dessen, M. A., \& Chagas, J. F. (2005). A ciência do desenvolvimento humano: Uma perspective interdisciplinar. In M. A. Dessen \& L. C. Aderson (Orgs.), A ciência do desenvolvimento humano: Tendências atuais e perspectivas futuras (pp. 19-36). Porto Alegre: Artmed.

Brasil. Ministério da Educação. (2001). Parecer CNE/CP n. 09/2001. Diretrizes curriculares nacionais para a formação de professores de educação básica, em nível superior, curso de licenciatura, de graduação plena. Recuperado em 12 janeiro 2006, de http:// www.mec.gov.br.

Brasil. Ministério da Educação. (2003). Estatísticas dos professores no Brasil. Recuperado em 12 janeiro, 2006, de http:// www.mec.gov.br.

Briceño, E. D. (1998). La creatividad como un valor dentro del proceso educativo. Psicologia Escolar e Educacional, 2, 43-51.

Castanho, M. E. L. M. A. (2000). A criatividade na sala de universidade. In I. P. Veiga \& M. E. L. M. A. Castanho (Orgs.), Pedagogia universitária: A aula em foco (pp. 75-89). São Paulo: Papirus.
Castanho, S., \& Castanho, M. E. L. M. A. (2000). $O$ que há de novo na educação superior: Do projeto pedagógico à prática transformadora. Campinas, SP: Papirus.

Chagas, J. F., Aspesi, C. C., \& Fleith, D. S. (2005). A relação entre criatividade e desenvolvimento: Uma visão sistêmica. In M. A. Dessen \& L. C. Aderson (Orgs.), A ciência do desenvolvimento humano: Tendências atuais e perspectivas futuras (pp. 210-228). Porto Alegre: Artmed.

Choi, J. N. (2004). Individual and contextual predictions of creative performance: The mediating role of psychological process. Creativity Research Journal, 16, 187-200.

Csikszentmihalyi, M. (1988). Society, culture, and person: A systems view of creativity. In R. J. Sternberg (Ed.), The nature of creativity (pp. 325339). New York: Cambridge University Press.

Csikszentmihalyi, M. (1996). Creativity: Flow and the psychology of discovery and invention. New York: HarperCollins.

Csikszentmihalyi, M. (1999). Implications of a systems perspective for the study of creativity. In R. J. Sternberg (Ed.), Handbook of creativity (pp. 313-335). New York: Cambridge University Press.

Cunha, M. I. (1998). O professor universitário na transmissão de paradigmas. Araraquara, SP: JM.

Dessen, M. A., \& Guedea, M. T. D. (2005). A ciência do desenvolvimento humano: Ajustando o foco de análise [Versão eletrônica]. Paidéia-Cadernos de Psicologia e Educação, 15, 11-20. Retirado em 14 maio 2007, de http://sites.ffclrp.usp.br/ paideia/artigos/30/03.htm.

Feldman, D. H. (1999). The development of creativity. In R. J. Sternberg (Ed.), Handbook of creativity (pp. 169-186). New York: Cambridge University Press.

Feldman, D. H., Csikszentmihalyi, M., \& Gardner, H. (Eds.). (1994). Changing the world: A framework for the study of creativity. Westport, CT: Praeger. 
Fleith, D. S. (2000). Teacher and students perceptions of creativity in the classroom environment. Roeper Review, 22, 148-153.

Fleith, D. S. (2002). Ambientes educacionais que promovem a criatividade e excelência. Sobredotação, 3, 27-39.

Forresti, S. M. P. S. (1999). A psicologia na formação de professores. In C. Witter (Org.), Ensino de psicologia (pp.75-94). Campinas, SP: Alínea.

Gall, M. D., Borg, W. R., \& Gall, J. P. (1996). Educational research (6th ed.). White Plains, NY: Longman.

Joly, M. C. R. A., \& Guerra, P. B. C. (2004). Compreensão em leitura e barreiras à criatividade: Um estudo com universitários ingressantes. PSICO, 35, 151-159.

Lara, A. T., Mosqueira, J. J., \& Ramos, M. G. (1998). A formação dos professores: Da gênese a incompletude. Revista Educação, 7, 23-24.

Ludke, M., \& Cruz, G. B. (2005). Aproximando universidade e escola de educação básica pela pesquisa. Cadernos de Pesquisa, 35(125), 81-109.

Martínez, A. M. (2002a). A criatividade na escola: Três direções de trabalho. Linhas Críticas, 8, 189-206.

Martínez, A. M. (2002b). Creatividad y salud en los individuos y en las organizaciones. Creatividady Sociedad, 1, 25-32.

Novaes, M. H. (2001). Modelos interpretativos da criatividade e alternativas de atuação psicossocioeducativa. In Z. A. Prette (Org.), Psicologia Escolar e Educacional (pp. 75-86). Campinas, SP: Alínea.

Novaes, M. H. (2003). O que se espera de uma educação no futuro. Psicologia Escolar e Educacional, 7, 155-160.

Picanço Diniz, C. W., \& Borges, R. (2000). Assimetrias da educação superior brasileira: Vários brasis e suas conseqüencias. Belém: EDUFPA.
Renzulli, J. S. (1992). A general theory for the development of creative productivity through the pursuit of ideal acts of learning. Gifted Child Quarterly, 36, 170-182.

Ruiz, V. M. (2004). Estratégias motivacionais: Estudo exploratório com universitários de um curso noturno de administração. Psicologia Escolar e Educacional, 8, 167-177.

Simonton, D. K. (1999). Creativity from a historiometric perspective. In R. J. Sternberg (Ed.), Handbook of creativity (pp. 116-133). New York: Cambridge University Press.

Silva, O., \& Alencar, E. M. L. S. (2003). Criatividade no ensino de Enfermagem: Enfoque triádico: Professor, aluno currículo. Revista Brasileira de Enfermagem, 56, 610-614.

Stein, M. I. (1974). Stimulating creativity: Group procedures. New York: Academic Press.

Sternberg, R. J., \& Lubart, T. I. (1991). An investment theory of creativity and its development. Human Development, 34, 1-31.

Sternberg, R. J., \& Lubart, T. I. (1995). Defying the crowd: Cultivating creativity in a culture of conformity. New York: The Free Press.

Tessaro, N. S., \& Guzzo, R. S. (2004). Auto-avaliação da competência para ensinar: Estudo preliminar de uma escola. Psicologia Escolar e Educacional, 8, 157-165.

Tolliver, J. M. (1985). Creativity university. Gifted Education International, 3, 32-35.

Weber, S. (2003). Profissionalização docente e políticas no Brasil. Educação \& Sociedade, 24. Retirado em 12 janeiro 2006, de http:// www.scielo.br/pdf/es/v24n85/a03v2485.pdf

Wechsler, S. M. (1993). Criatividade: Desenvolvendo e encorajando. Campinas, SP: Psy.

Wechsler, S. M. (2002). Criatividade e desempenho escolar: Uma síntese necessária. Linhas Críticas, 8, 179- 188 . 
416 Paidéia, 2007, 17(38), 403-416

Artigo recebido em 19/02/2007.

Aceito para publicação 15/09/2007.

Esta pesquisa, que obteve apoio do CNPq, é parte da dissertação de mestrado da primeira autora orientada pela segunda autora.

Endereço para correspondência:

SHIS QI 05 cj 02 casa 11, Lago Sul. CEP: 71615-020, Brasília-DF, Brasil. E-mail: rejane.arrudaribeiro@gmail.com

Rejane Arruda Ribeiro é Mestre em Psicologia pela Universidade de Brasília, pesquisadora do Centro de Formação de Recursos Humanos em Transportes desta instituição.

Denise de Souza Fleith é Ph.D. em Psicologia Educacional pela University of Connecticut, professora do Programa de Pósgraduação em Processos de Desenvolvimento Humano e Saúde da Universidade de Brasília, pesquisadora do CNPq. 